Josephine F.L. Lox, Franziska Eichler, Talha Erdem, Marcus Adam, Nikolai Gaponik, Hilmi Volkan Demir, Vladimir Lesnyak* and Alexander Eychmüller

\title{
Brightly Luminescent Cu-Zn-In-S/ZnS Core/Shell Quantum Dots in Salt Matrices
}

https://doi.org/10.1515/zpch-2017-1086

Received November 30, 2017; accepted January 25, 2018

Abstract: In the past decades cadmium-free quantum dots (QDs), among which are quaternary colloidal Cu-Zn-In-S/ZnS (CZIS/ZnS) core/shell nanocrystals (NCs), have attracted great scientific interest. Particularly, their low toxicity and the possibility to tune their photoluminescence (PL) properties by varying the composition in the multicomponent system make them highly attractive for applications in light-emitting diodes (LEDs). Thus, the demands for high quality CZIS/ ZnS QDs and methods to process them into bulk materials stimulate investigations of these nanomaterials. Herein, we demonstrate the synthesis of CZIS/ZnS core/shell NCs via a surfactant induced nucleation process, which emit in various colors covering the range from $520 \mathrm{~nm}$ to $620 \mathrm{~nm}$ possessing high photoluminescence quantum yields (PLQYs) up to $47 \%$. Furthermore, the as synthesized $\mathrm{NCs}$ were successfully integrated into two different salt matrices $\left[\mathrm{Na}_{2} \mathrm{~B}_{4} \mathrm{O}_{7}\right.$ (Borax) and $\mathrm{LiCl}]$ using two different approaches. The commonly used incorporation of the NCs into Borax salt led to salt crystals emitting from $540 \mathrm{~nm}$ to $600 \mathrm{~nm}$ with PLQYs up to $24 \%$. By encapsulating the QDs into LiCl, brightly emitting NCs-in$\mathrm{LiCl}$ powders with the PL covering a range from $520 \mathrm{~nm}$ to $650 \mathrm{~nm}$ with PLQYs of up to $14 \%$ were obtained. As a proof of concept, the fabrication of a color conversion LED using NCs encapsulated into $\mathrm{LiCl}$ demonstrated the applicability of the encapsulated NCs.

Keywords: copper zinc indium sulfide; encapsulation; LED; photoluminescence; quantum dots; salt crystals; semiconductor nanocrystals.

\footnotetext{
*Corresponding author: Vladimir Lesnyak, Physical Chemistry, TU Dresden, Bergstr. 66b, 01062 Dresden, Germany, e-mail: vladimir.lesnyak@chemie.tu-dresden.de Josephine F.L. Lox, Franziska Eichler, Marcus Adam, Nikolai Gaponik and Alexander Eychmüller: Physical Chemistry, TU Dresden, Bergstr. 66b, 01062 Dresden, Germany Talha Erdem and Hilmi Volkan Demir: Department of Electrical and Electronics Engineering, Department of Physics, and UNAM-Institute of Materials Science and Nanotechnology, Bilkent University, TR-06800 Ankara, Turkey
} 


\section{Introduction}

Colloidal semiconductor nanocrystals (NCs), also known as quantum dots (QDs), have gained great scientific interest within the past decades. With sizes in the quantum confinement regime, their unique size- and shape dependent optoelectronic properties impart them a great potential to serve as materials employed in optoelectronic devices [1-3]. To date, mainly binary II-VI, III-V and IV-VI compounds $\mathrm{MX}\left(\mathrm{M}^{2+}=\mathrm{Cd}^{2+}, \mathrm{Hg}^{2+}, \mathrm{Pb}^{2+} ; \mathrm{M}^{3+}=\mathrm{In}^{3+} ; \mathrm{X}^{2-}=\mathrm{S}^{2-}, \mathrm{Se}^{2-}, \mathrm{Te}^{2-}\right.$; $\mathrm{X}^{3-}=\mathrm{P}^{3-}$ ) have been studied. Despite of their advantages, in particular for electronic and photovoltaic applications, they contain toxic elements $(\mathrm{Cd}, \mathrm{Hg}$ and $\mathrm{Pb}$ ) which display a big risk for the environment [4, 5]. Consequently, copper chalcogenide-based ternary and quaternary compounds, e.g. CuInS 2 NCs (CIS, CZIS) and $\mathrm{CuInS}_{2} / \mathrm{ZnS}$ core/shell NCs (CIS/ZnS, CZIS/ZnS), have moved into the focus of research, presenting outstanding alternatives to the II-VI and IV-VI families of semiconductor nanomaterials. Especially, their low-toxicity is advantageous and enables widening the range of applications. As an example, in vivo imaging of intracellular biological processes is feasible and can be exploited in the red and near-infrared region $(650-830 \mathrm{~nm})[6,7]$. Additionally, CIS NCs have been frequently used in photovoltaic devices as they possess a direct bandgap of $\mathrm{E}_{\mathrm{g}}=1.53 \mathrm{eV}$ with a large extinction coefficient $\left(10^{5} \mathrm{M}^{-1} \mathrm{~cm}^{-1}\right)$ [8]. In contrast to the binary semiconductor NCs, the energy bandgap of ternary CIS and quaternary CZIS NCs is tuned not only by varying the size of the NCs, but also by varying the composition of the multi-component system, which facilitates achieving a specific range of emission wavelengths [9-12]. So far, the control of the reaction stoichiometry in the one-pot synthesis remains a major challenge in fabricating ternary/quaternary CIS/CZIS compounds as precursor reactivities strongly differ [13].

Since these copper chalcogenide-based nanoparticles are quite sensitive to environmental conditions, for example to the presence of oxygen which can lead to a gradual oxidation of their surface, in particular $\mathrm{Cu}^{+}$ions can be oxidized to $\mathrm{Cu}^{2+}$, the as synthesized NCs should be properly isolated from the environment aiming at long term applications. One of the ways to protect these NCs is to incorporate them into a stable polymer matrix, such as polymethacrylate or polystyrene [14, 15]. These QDs-in-polymer composites hold great promise for applications in photovoltaic windows and solar concentrators [15-17]. Another strategy of encapsulation of QDs has recently been developed by our group, which consists in embedding nanoparticles in salt crystals [18-26]. The resulting composites exhibit bright fluorescence and excellent stability against (photo) oxidation, and thus can be used as color converters in LEDs. Commonly, in these devices the emission intensity of unprotected QDs decreases significantly 
because of the steady exposure to energetic photons as well as high temperatures [27]. To circumvent this problem, our group investigated the incorporation of aqueous NCs in a single phase process into salt crystals ( $\mathrm{NaCl}, \mathrm{KCl}$, etc.) which led to an improvement of the emission stability [18]. Moreover, in a further study we were able to demonstrate an improvement of the photoluminescence quantum yields (PLQYs) of the NCs in salt crystals [19]. Based on the singlephase approach, we extended the integration method to plasmonic systems and indicated a surface plasmon enhanced fluorescence of QDs combined with metal nanoparticles, which were co-embedded in sucrose host crystals $[27,28]$. All studies have focused on the integration of aqueous NCs into host crystals. In order to apply this method to QDs capped with non-polar organic ligands, an additional step, the ligand exchange, is required prior to the incorporation [27]. This type of QDs is known to possess intrinsically high PLQYs and narrow emission bandwidths, which are especially needed for light emission applications [27]. Furthermore, Erdem et al. [27] demonstrated the direct encapsulation of lyophilic QDs into $\mathrm{LiCl}$ salt, which does not need a prior ligand exchange due to the solubility of $\mathrm{LiCl}$ and the dispersibility of the particles in tetrahydrofuran. The LiCl-encapsulation was investigated for green emitting $\mathrm{CdSe} / \mathrm{Cd}_{\mathrm{x}} \mathrm{Zn}_{1-\mathrm{x}} \mathrm{Se}_{\mathrm{y}} \mathrm{S}_{1 \text { - }}$ ${ }_{y} / \mathrm{ZnS} \mathrm{NCs}$ and the increased emission stability was proven while the emission intensity decreased (from 95.5\% to 34.7\%) [27].

In this work, we report a synthetic approach to brightly luminescent CZIS/ $\mathrm{ZnS}$ core/shell NCs in one pot reaction. The control of the size and the composition of the NCs is enabled by the addition of oleylamine at $180{ }^{\circ} \mathrm{C}$ which triggers the overall nucleation and thus facilitates the growth of particles with low polydispersity [13]. By varying the initial precursor ratios from $\mathrm{Zn}: \mathrm{Cu}=1.8$ to $\mathrm{Zn}: \mathrm{Cu}=11$, the emission colors could be tuned in the range of 520-620 nm. Using these QDs we, for the first time, investigated their incorporation into salt matrices $\left[\mathrm{Na}_{2} \mathrm{~B}_{4} \mathrm{O}_{7}\right.$ (Borax) and $\left.\mathrm{LiCl}\right]$. We analyzed the changes of the emission properties as a result of the embedding by the two different strategies. As a proof of concept, a color conversion LED with the CZIS/ZnS core/shell NCs-in-LiCl powders with the highest quantum efficiency was fabricated and tested.

\section{Experimental section}

Copper(I) iodide (CuI, 99.99\%), indium(III) acetate [In(OAc), 99.99\%], lithium chloride ( $\mathrm{LiCl}$, anhydrous, 99\%), sulfur (S, 99.98\%), zinc diethyldithiocarbamate $\left[\mathrm{Zn}\left(\mathrm{S}_{2} \mathrm{CNEt}_{2}\right)_{2}, 97 \%\right]$, zinc stearate $\left(\mathrm{Zn}\left(\mathrm{C}_{18} \mathrm{H}_{35} \mathrm{O}_{2}\right)\right.$, purum), chloroform $\left(\mathrm{CHCl}_{3}\right.$, 99\%), 3-mercaptopropionic acid (MPA, 99\%), octadecene (ODE, technical grade, 90\%), oleic acid (99\%), oleylamine (OlAm, 70\%), tetrahydrofuran (THF, 99.9\%), 
toluene ( $\geq 99.7 \%$ ), were purchased from Sigma Aldrich. Anhydrous methanol (99.9\%) was purchased from VWR and 1-dodecanethiol (DDT, $\geq 99$ ) was purchased from Alfa Aesar. Tri-n-octylphosphine (TOP, 97\%) was purchased from ABCR and Borax (99\%) was purchased from Fluka. All chemicals were used without any further purification.

\subsection{Synthesis of CZIS NCS}

CZIS core NCs were synthesized according to a recipe published by Hsing-Ju Pan et al. [13]. First, a mixture of $5.7 \mathrm{mg} \mathrm{CuI}(0.03 \mathrm{mmol}), 87.5 \mathrm{mg} \mathrm{In}(\mathrm{OAc})_{3}(0.3 \mathrm{mmol})$ and $39.8 \mathrm{mg} \mathrm{Zn}\left(\mathrm{S}_{2} \mathrm{CNEt}_{2}\right)_{2}(0.11 \mathrm{mmol})$ in $4 \mathrm{~mL} \mathrm{ODE}, 0.127 \mathrm{~mL}$ oleic acid and $0.24 \mathrm{~mL}$ DDT was degassed in a three-neck round-bottom $25 \mathrm{~mL}$ flask under vacuum and vigorous stirring at room temperature for $1 \mathrm{~h}$. Then, the flask was filled with argon and the temperature increased to $180^{\circ} \mathrm{C}$, thereafter $2 \mathrm{~mL} \mathrm{OlAm}$ was added and the reaction mixture was maintained at $180{ }^{\circ} \mathrm{C}$ for $1 \mathrm{~h}$. Upon adding different amounts of $\mathrm{Zn}\left(\mathrm{S}_{2} \mathrm{CNEt}_{2}\right)_{2}$, the $\mathrm{NC}$ composition varied resulting in green ( $0.33 \mathrm{mmol} ; \mathrm{Zn}: \mathrm{Cu}=11)$, yellow (0.22 mmol; $\mathrm{Zn}: \mathrm{Cu}=7.3)$, orange (0.11 mmol; $\mathrm{Zn}: \mathrm{Cu}=3.6)$ and red $(0.055 \mathrm{mmol} ; \mathrm{Zn}: \mathrm{Cu}=1.8)$ emitting samples. As soon as the emission peak wavelength remained constant (after $\sim 30$ min of reaction), an aliquot of the reaction mixture was cooled down to room temperature and was cleaned by precipitation with methanol and redispersion in toluene repeated twice.

\subsection{ZnS-shell growth}

In order to synthesize CZIS/ZnS core/shell NCs, $0.5 \mathrm{~mL}$ of a Zn-precursor containing $31.6 \mathrm{mg}$ zinc stearate $(0.05 \mathrm{mmol})$ in $0.5 \mathrm{~mL}$ ODE dissolved under inert atmosphere was injected into the crude CZIS NC solution (see the previous part). The temperature of the shell growth was increased to $210^{\circ} \mathrm{C}$ and maintained for $40 \mathrm{~min}$ followed by cooling the reaction mixture to room temperature. For the purification of the resulting CZIS/ZnS NCs the same procedure as for the core NCs was employed. In order to improve the shell coating and to widen the range of emission, in a second series of experiments, CZIS NC cores were coated by using the same Zn-precursor and adding $2 \mathrm{~mL}$ of TOP:S (prepared by dissolving $6.4 \mathrm{mg}$ $\mathrm{S}$ powder $(0.2 \mathrm{mmol})$ in $2 \mathrm{~mL}$ TOP $)$. 


\subsection{Phase transfer of CZIS/ZnS NCs and embedding into Borax}

For the phase transfer of the NCs $50 \mu \mathrm{L}$ of the cleaned CZIS/ZnS NCs were diluted in $450 \mu \mathrm{L} \mathrm{CHCl}_{3}$ and stirred with $2 \mathrm{~mL}$ of $0.2 \mathrm{M}$ aqueous MPA solution with $\mathrm{pH} 9$ adjusted by addition of concentrated $\mathrm{NaOH}$ for $2 \mathrm{~h}$ at $70{ }^{\circ} \mathrm{C}$ [29]. Afterwards, the aqueous phase was separated and used without any further purification for embedding into the salts. In order to prepare QDs-in Borax composites, $1 \mathrm{~mL}$ of the aqueous CZIS/ZnS NCs were added to $5 \mathrm{~mL}$ of a saturated Borax solution and stored in an oven at $30{ }^{\circ} \mathrm{C}$ for 3 days. As soon as the supernatant did not show emission anymore, the crystallization was finished and the crystals were separated from the solution, rinsed with cold water and dried for 1 day.

\subsection{Preparation of the NCs-in-LiCl composite}

Prior to the encapsulation of the CZIS/ZnS NCs into LiCl, toluene from the NCs dispersion (50-200 $\mu \mathrm{L}$ - depending on the sample concentration) was evaporated. The NCs were redispersed in $250 \mu \mathrm{L}$ THF and $1 \mathrm{~mL}$ of a LiCl stock solution $(1.83 \mathrm{~g}$ $\mathrm{LiCl}$ dissolved in $50 \mathrm{~mL}$ THF under inert atmosphere) was slowly added. Subsequently, the solvent was evaporated completely by the use of a desiccator for $2 \mathrm{~h}$ to obtain the $\mathrm{LiCl}$ encapsulated NCs.

\subsection{Preparation of NCs-in-LiCl films on a conventional LED}

For the preparation of the NCs-in-LiCl films, $15 \mathrm{mg}$ of the embedded LiCl powder were mixed with $30 \mathrm{mg}$ of a commercial two-component epoxy glue (Bison) and deposited directly on a LED (blue emitting $1 \mathrm{~W}$ InGaN LED chip, part number: ASMT-MB00). Without any additional treatment, the composite of NCs-in-LiCl with epoxy glue hardened within $30 \mathrm{~min}$.

\subsection{Transmission electron microscopy (TEM)}

The samples for TEM measurements were prepared by drop casting a diluted $\mathrm{NC}$ dispersion onto a carbon coated copper grid with subsequent evaporation of the solvent. Conventional TEM measurements were carried out on a JOEL JEM1400 microscope equipped with a thermionic gun (W filament) working at $120 \mathrm{kV}$ accelerating voltage. 


\subsection{UV-VIS absorption spectroscopy}

Absorption spectra of NCs dispersed in toluene were acquired on a Carry 50 UV-VIS spectrophotometer (Varian) using $1 \mathrm{~cm}$ path length quartz cuvettes.

\subsection{Photoluminescence measurements}

For acquiring the PL spectra, the NC dispersion was diluted with toluene and measured on a Horiba Jobin Yvon FluoroLog ${ }^{\circledR}$-3-spectrofluorometer using an excitation wavelength of $450 \mathrm{~nm}$. The PLQY of the NC dispersion was determined by using a method published by Grabolle et al. [30] requiring the following steps: (1) measurement of the absorption and PL of the NC dispersions, (2) measurement of the absorption and PL of a corresponding standard dye with known PLQY absorbing and emitting within a similar wavelength region as the sample (Rhodamine 6G and Rhodamine 101 in ethanol), (3) calculation of the relative PLQY by using Eq. 1 where $x$ and st represent the sample and the standard, $F$ is the spectrally integrated photon flux $q_{p}\left(\lambda_{e m}\right)$ at the detector, $n_{i}^{2}$ is the refractive index correction term (has to be applied if different solvents are used for the sample and the standard, $f\left(\lambda_{e x}\right)$ is the fraction of the excitation light absorbed by the chromophore:

$$
\phi_{f, x}=\phi_{f, s t} \times \frac{F_{x}}{F_{s t}} \times \frac{f_{s t}\left(\lambda_{e x}\right)}{f_{x}\left(\lambda_{e x}\right)} \times \frac{n_{x}^{2}}{n_{s t}^{2}} .
$$

For the determination of the PLQY of the NCs-in-salts a Spectral Products monochromator with integrated xenon lamp, a Hamamatsu integrating sphere, and an Ocean Optics Maya 2000 spectrometer were used with an excitation wavelength of $460 \mathrm{~nm}$ following the method described by de Mello et al. [31]. This technique requires the measurements of (1) the spectrum without a sample placed in the integrating sphere, (2) the spectrum of the sample when the sample is excited at $460 \mathrm{~nm}$ directly by the light source (sample placed at a slightly oblique angle as suggested), and (3) the rotated sample illuminated by the light scattered from the surface of the integrating sphere. The PLQY $(\eta)$ is then calculated using the Eq. 2 where $E$ represents the excitation part of the spectrum, $L$ indicates the emission part of the acquired spectrum and the indices 1, 2, 3 express the measurement steps described above:

$$
\eta=\frac{L_{2}-\frac{E_{2} L_{3}}{E_{3}}}{\left(1-\frac{E_{2}}{E_{3}}\right) E_{1}}
$$




\section{Results and discussion}

Aiming on the preparation of highly stable and efficient color converting crystals for color enrichment of LEDs, we investigated the encapsulation of CZIS/ ZnS core/shell QDs into Borax and LiCl salts. In this work, first CZIS/ZnS NCs were synthesized in a two-step hot-injection method following a recipe published by Hsing-Ju Pan et al. [13]. In the first step, CZIS core NCs were obtained by a surfactant induced nucleation process. The composition of the resulting NCs was varied by changing the amount of Zn-precursor in the reaction mixture and thus the initial $\mathrm{Zn}: \mathrm{Cu}$ ratio $(1.8,3.6,7.3$, 11), while maintaining the initial $\mathrm{Cu}$ :In ratio constant. In order to further increase the stability of the NC cores, a gradient $\mathrm{ZnS}$ shell was grown in the second step based on a partial cation exchange reaction on the surface of the particles resulting in CZIS/ZnS core/ shell NCs. To increase the PLQY of these core/shell nanoparticles and to widen the PL range, we modified the shell growth procedure by the addition of TOP:S into the reaction mixture yielding, in addition to a partial cation exchange, a pure ZnS shell overgrown on the ZnS-rich surface. These two shell growth methods led to a variety of CZIS/ZnS NCs with PL spectra covering the visible range from $520 \mathrm{~nm}$ to $620 \mathrm{~nm}$. The CZIS/ZnS NCs synthesized without TOP:S were phase transferred and integrated into the ionic matrices, whereas the series of CZIS/ZnS NCs obtained with TOP:S were encapsulated in LiCl resulting in NCs-in-LiCl powders. One of the powders with PLQY $=13 \%(\mathrm{Zn}: \mathrm{Cu}=1.8)$ was employed in the fabrication of a LED prototype. A general scheme of the work is shown in Figure 1.

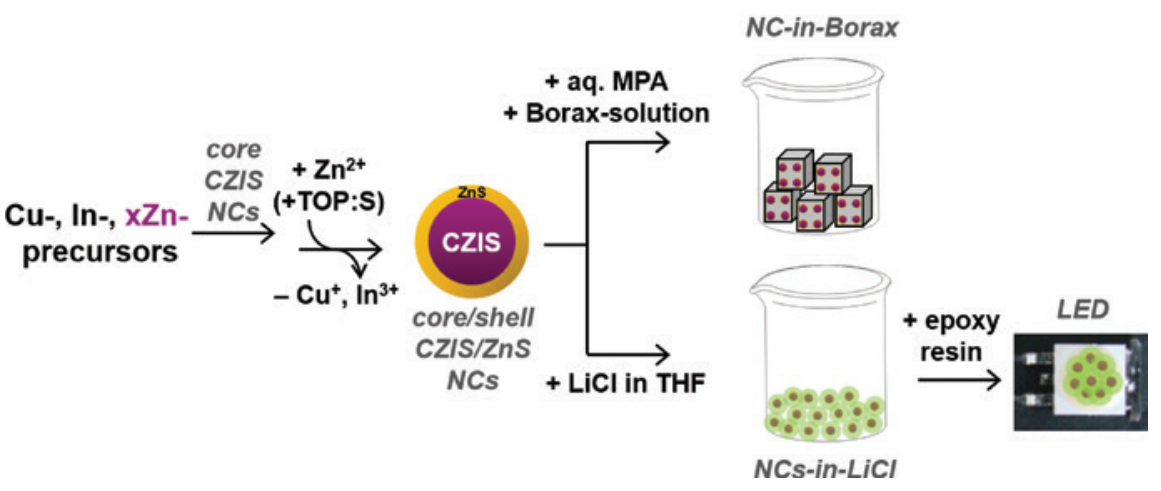

Fig. 1: A scheme of the work including the synthesis of CZIS/ZnS NCs with varied composition, the crystallization of NCs-in-salt composites and their integration into a LED. 


\subsection{Synthesis of CZIS/ZnS core/shell NCs}

In the first step of the synthesis, CZIS NC cores were obtained by a hot-injection method. By the use of relatively inert precursors that form stable complexes ( $\mathrm{Cu}-$ DDT and In-oleate) the nucleation would not take place at a moderate temperature $\left(180{ }^{\circ} \mathrm{C}\right)$ until $\mathrm{Zn}\left(\mathrm{S}_{2} \mathrm{CNEt}_{2}\right)_{2}$ decomposition starts, which is triggered by the injection of OlAm [13]. Zinc diethyldithiocarbamate acts as a source for $\mathrm{Zn}$ and $\mathrm{S}$ starting the nucleation and, thus, enables a homogenous size distribution of the CZIS NCs [13]. The composition of the NCs is controlled by the initial Cu:In:Zn ratio. While the $\mathrm{Cu}$ :In ratio remains constant (1:10), the amount of $\mathrm{Zn}\left(\mathrm{S}_{2} \mathrm{CNEt}_{2}\right)_{2}$ can be varied in order to tune the composition depending optical properties of the resulting QDs. Aiming at the variation of PL properties, a series of CZIS NC syntheses with molar ratios of $\mathrm{Zn}: \mathrm{Cu}=1.8,3.6,7.3$ and 11 have been performed.

In the second step, the thus obtained CZIS NC cores have been coated with a $\mathrm{ZnS}$ shell in order to further increase their photostability and to protect them from the oxidative environment. By the injection of zinc stearate into the crude solution, $\mathrm{Zn}^{2+}$ cations partially exchange $\mathrm{Cu}^{+}$and $\mathrm{In}^{3+}$ cations on the surface of the CZIS NCs and thus form a gradient ZnS shell (quaternary alloy structure) [13]. Figure SI1 (in the Supporting Information) displays TEM images of the resulting CZIS/ZnS core/shell NCs showing fairly monodisperse spherical particles with a diameter of approximately $3 \mathrm{~nm}$. The core/shell NCs were further characterized by means of absorption and PL spectroscopy (Figure 2a,b). CZIS/ZnS NCs exhibit a featureless absorption, which is a common property of ternary/ quaternary complex copper chalcogenide-based nanoparticles. The absence of well-defined transitions is mainly explained by inhomogeneous size/composition distributions of the particles within one sample [10, 32]. Nevertheless, for the series of CZIS/ZnS NCs with different $\mathrm{Zn}: \mathrm{Cu}$ ratios the absorption spectrum enables a first insight into the change of the optical properties with the composition. Starting with a $\mathrm{Zn}$ :Cu ratio of 1.8 the further increase of $\mathrm{Zn}$-precursor content leads to a blue-shift of the absorption onset from 603 to $515 \mathrm{~nm}$ due to a widening of the band gap. A more pronounced dependency of the composition on the optical properties can be observed by means of PL measurements. By increasing the amount of $\mathrm{Zn}$ in the reaction mixture, the PL maximum of the resulting QDs shifts from $619 \mathrm{~nm}$ to $537 \mathrm{~nm}$ (from $\mathrm{Zn}: \mathrm{Cu}=1.8$ to $\mathrm{Zn}: \mathrm{Cu}=11$ ). As the bandgap of the NCs is located between those of $\mathrm{ZnS}$ and $\mathrm{CuInS}_{2}$, the valence and conduction bands can be fine-tuned by varying the composition of the particles by the addition of different amounts of zinc diethydithiocarbamate in the first step of the synthesis $[13,33,34]$. The $\mathrm{ZnS}$ shell grown in the next step passivates surface defects on the core NCs responsible for non-radiative recombinations leading to an increased PLQY of up to $48 \%$ for the core/shell NCs with an initial ratio of 

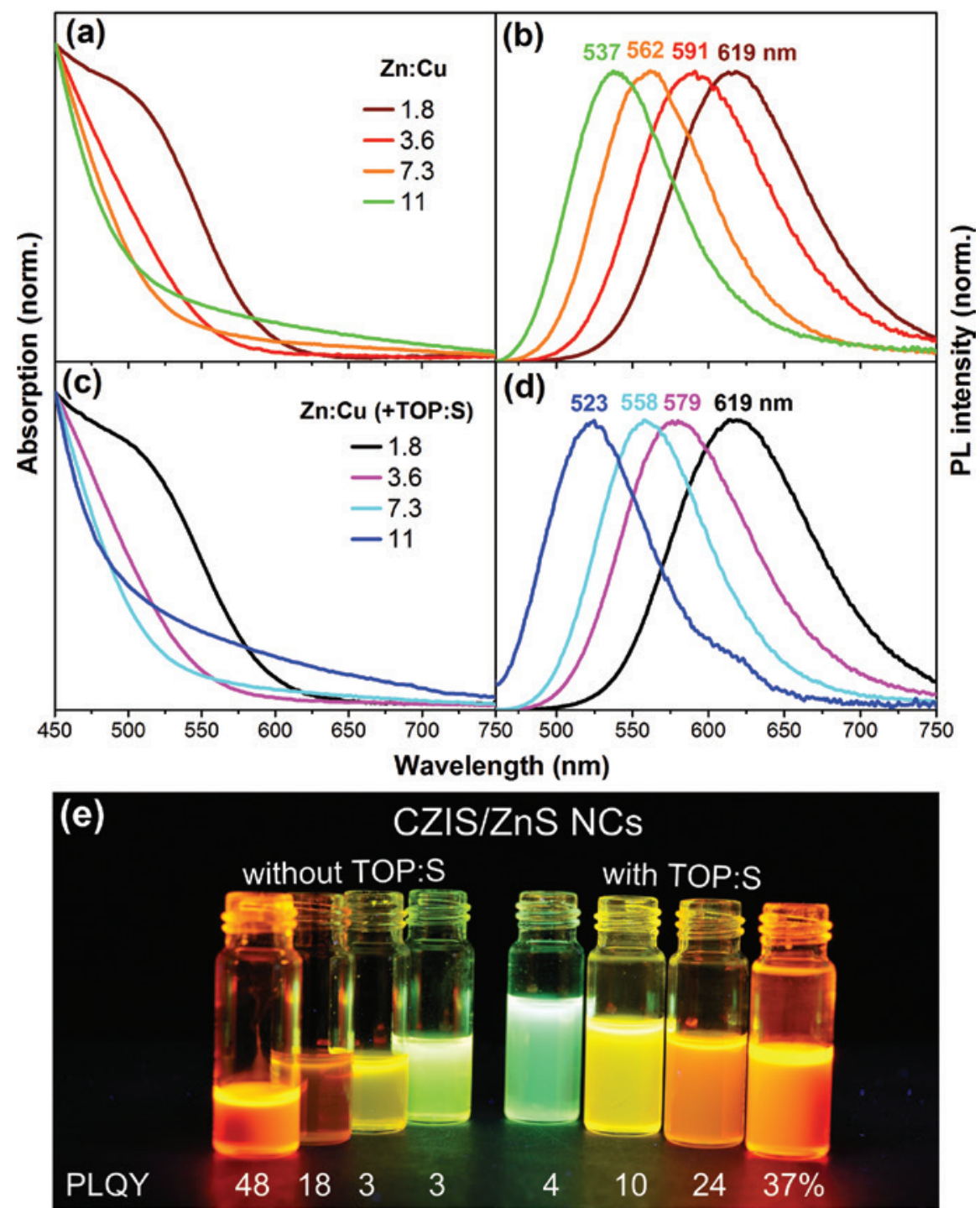

Fig. 2: Absorption (a, c) and PL (b, d) spectra of CZIS/ZnS NCs obtained with initial ratio $\mathrm{Zn}: \mathrm{Cu}=1.8-11$ with (c) and without (d) addition of TOP:S in the shell growth step. Photo of NC dispersions under UV-light with their PLQY values (e).

$\mathrm{Zn}: \mathrm{Cu}=1.8$. A further increase of the $\mathrm{Zn}$ amount results rather in a PLQY decrease, for example by adding the $\mathrm{Zn}$-precursor with a ratio $\mathrm{Zn}: \mathrm{Cu}=11$ the PLQY dropped to $3 \%$. 
In order to increase the PLQY, especially for the samples with the initial ratios $\mathrm{Zn}: \mathrm{Cu}=7.3$ and 11, TOP:S was added into the reaction mixture for the shell growth. This precursor has several effects on the CZIS/ZnS NC formation. First, according to Pearson's Hard-Soft Acid-Base concept, TOP primarily acts as a soft base complexing the soft acid $\mathrm{Cu}^{+}$ions, thus facilitating the $\mathrm{Zn}^{2+} \rightarrow \mathrm{Cu}^{+}$cation exchange [35]. Second, TOP is known as a ligand, which stabilizes the core/ shell NCs additionally decreasing the amount of defects that are responsible for non-radiative recombination pathways and, thus, leads to an enhancement of the PLQY. This shelling procedure has been carried out for the set of initial $\mathrm{Zn}: \mathrm{Cu}$ ratios from 1.8 to 11 . The addition of TOP:S to the shell coating step does not influence the size or the shape of the particles as can be seen from the TEM image in Figure SI1b. Thus obtained CZIS/ZnS NCs have further been characterized by means of absorption and PL measurements (Figure 2c,d). As in the case of the first shell growth method, the absorption spectra of the resulting NCs are featureless and do not exhibit well-defined absorption peaks. Absorption onsets are blue-shifted with increasing $\mathrm{Zn}: \mathrm{Cu}$ from $614 \mathrm{~nm}$ to $507 \mathrm{~nm}$. The PL spectra of these NCs give a further insight into the change of their optical properties (Figure 2d). In comparison to the synthesis without TOP:S, a further small blueshift of the PL maxima in the range of 4-14 $\mathrm{nm}$ is observed for $\mathrm{Zn}: \mathrm{Cu}=3.6,7.3$ and 11 (see Figure 3a). Thus, on one hand, the addition of TOP:S enables an acceleration of the $\mathrm{Zn}^{2+} \rightarrow \mathrm{Cu}^{+}$cation exchange. On the other, the reaction of TOP:S with Zn-precursor should lead to a thicker ZnS shell, which however is difficult to prove by the TEM imaging due to the small size of the particles. By this, the amount of incorporated $\mathrm{Zn}$ depends on the initial composition of the CZIS core $\mathrm{NCs}$, and no further blue shift can be observed for $\mathrm{Zn}: \mathrm{Cu}=1.8$. As follows from Figure $3 \mathrm{~b}$, the PLQY values increase for the samples with $\mathrm{Zn}: \mathrm{Cu}=3.6,7.3$ and
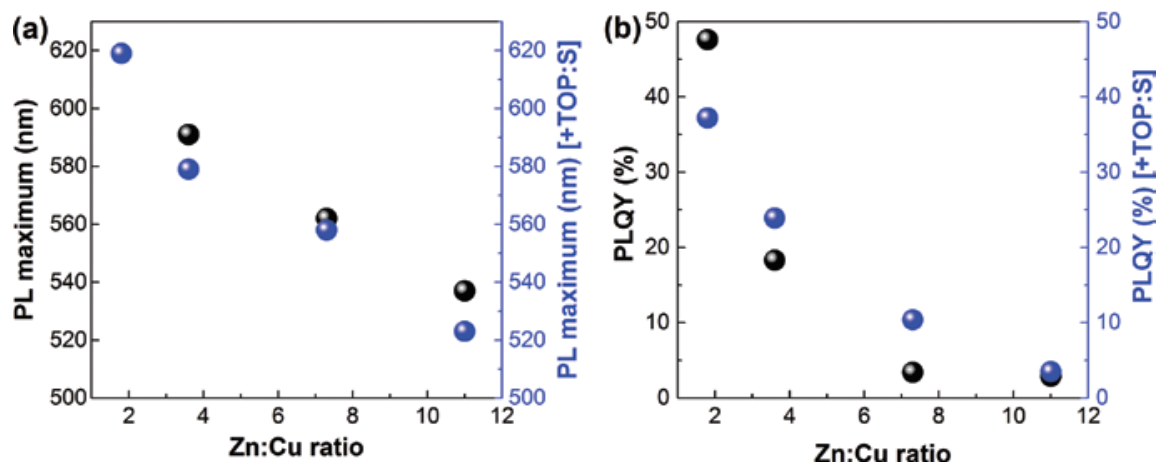

Fig. 3: Comparison of PL maxima (a) and PLQYs (b) of CZIS/ZnS NCs synthesized by varying initial ratio of $\mathrm{Zn}$ :Cu from 1.8 to 11 with and without TOP:S in the shell growth step. 
11 with the addition of TOP:S, in comparison to the samples synthesized without TOP:S, whereas the PLQY of the sample with $\mathrm{Zn}: \mathrm{Cu}=1.8$ decreases. The positions of the PL maxima and the PLQY values of the CZIS/ZnS NCs synthesized with and without TOP:S are summarized in Table SI1.

\subsection{Preparation of CZIS/ZnS NCs-in-Borax}

Before incorporation of the NCs into Borax, they were transferred from organic solutions to water using a ligand exchange technique. For the ligand exchange we used an aqueous solution of MPA and $\mathrm{NaOH}$ with $\mathrm{pH}$ 9. After stirring the twophase mixture, the NCs synthesized using $\mathrm{Zn:Cu}=3.6$, 7.3 and 11 ratios (without TOP:S) moved to the water phase, whereas the phase transfer of the sample with $\mathrm{Zn}: \mathrm{Cu}=1.8$ was unsuccessful. Subsequently, the crystallization process followed recipes adapted from the literature [36-38]. The phase transferred NCs were mixed with a saturated Borax solution. A slow evaporation of water leading to the oversaturation of the salt solution and consequently to the crystallization of the NCs-in-Borax composite occurred by keeping the samples in an oven at $30{ }^{\circ} \mathrm{C}$ for 3 days. The resulting NCs-in-Borax crystals were then separated and carefully rinsed with cold water in order to remove not embedded NCs and impurities from the surface [18]. All samples were characterized by means of PL spectroscopy. As can be seen in Figure 4 the PL spectra of the composites are similar to those of the

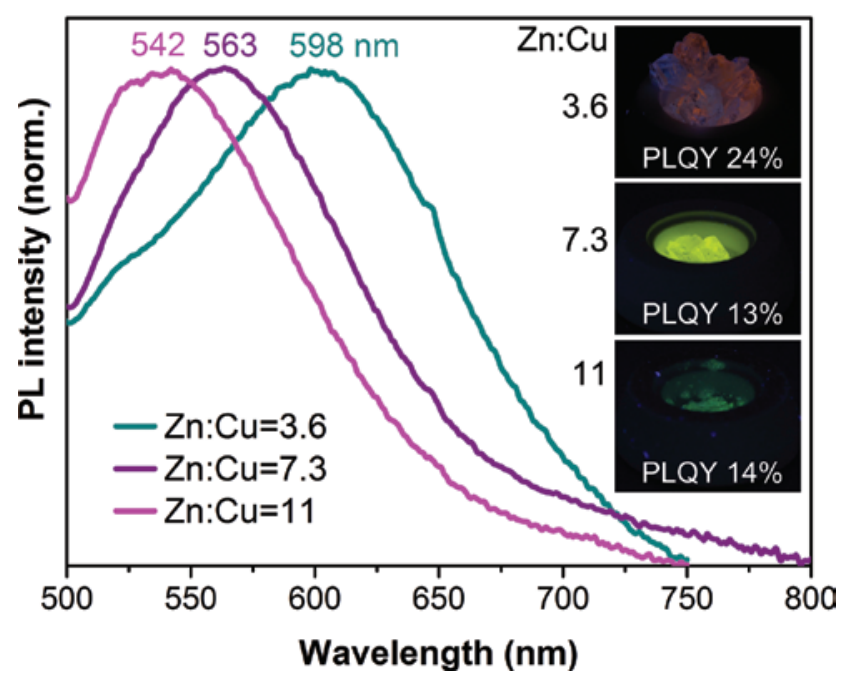

Fig. 4: PL spectra of CZIS/ZnS NCs embedded into Borax salt with initial ratios of $\mathrm{Zn:Cu}=3.6$, 7.3 and 11. Inset: photos of the corresponding composites with PLQY values. 

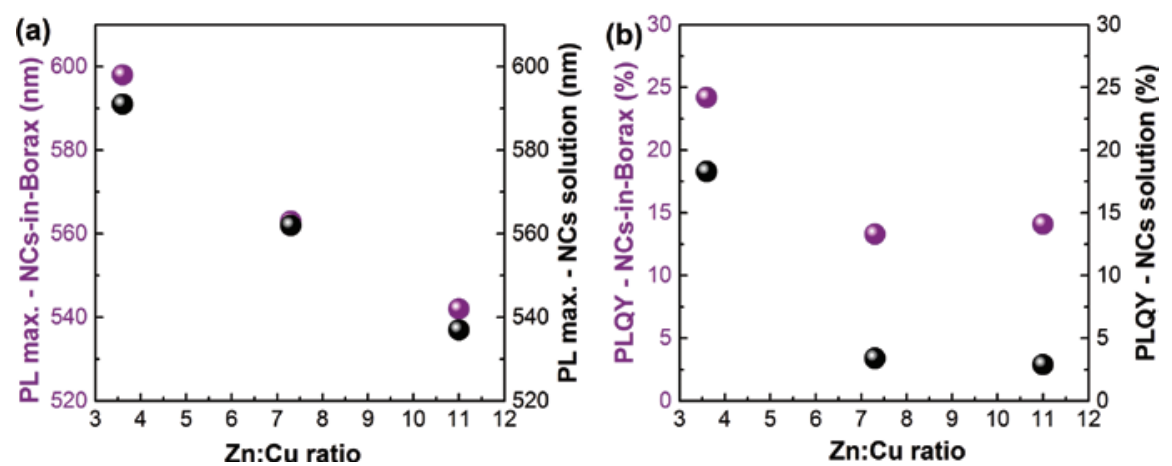

Fig. 5: Comparison of PL maxima (a) and PLQYs (b) of CZIS/ZnS NCs (obtained with initial ratios $\mathrm{Zn}: \mathrm{Cu}=3.6,7.3$ and 11$)$ and corresponding NCs-in-Borax composites.

NCs in solution with PL maxima ranging from $542 \mathrm{~nm}$ to $598 \mathrm{~nm}$ depending on the initial $\mathrm{Zn}: \mathrm{Cu}$ ratio. Compared to the PL maxima of the NCs in solution, a red shift is observed for each composite sample, which is mostly related to the change in dielectric constant of the surrounding media (Figure 5a and Table SI2). In addition, the reabsorption of the blue part of the spectra in optically dense samples contributes to the shift of emission $[18,19]$. The PLQYs of the NCs-in-Borax vary from $13 \%$ to $24 \%$. As seen in Figure $5 \mathrm{~b}$ and Table SI2, the incorporation of the NCs into the salt resulted in an improvement of the PLQYs for each sample with an especially pronounced PL enhancement in the case of $\mathrm{Zn}: \mathrm{Cu}=7.3$ and 11 samples. Depending on the initial PLQY of the NCs in solution the factor of enhancement varies from 1.3 for the parent NCs emitting already strong in solution to more than four for the samples with initially low PLQY. The PLQY enhancement of NCs-insalts was already observed for CdTe QDs [19, 39]. Two main reasons were suggested for this phenomenon: the changes in radiative and non-radiative rates and the changes in the refractive index of the media $[19,39]$. Thus, the embedding of CZIS/ZnS NCs into Borax salt enables the formation of brightly fluorescent solid composites.

\subsection{Preparation of CZIS/ZnS NCs-in-LiCl}

For the encapsulation of the CZIS/ZnS NCs (synthesis with TOP:S, initial ratios $\mathrm{Zn}: \mathrm{Cu}=1.8-11)$ into $\mathrm{LiCl}$ they were dispersed in THF and then mixed with a stock solution of $\mathrm{LiCl}$ in THF followed by evaporation of the solvent under vacuum. The PL spectra of thus obtained NCs-in-LiCl powders are similar to those of the initial NC dispersions (cf. Figures $2 \mathrm{~d}$ and $6 \mathrm{~b}$ ), showing relatively broad emission. 


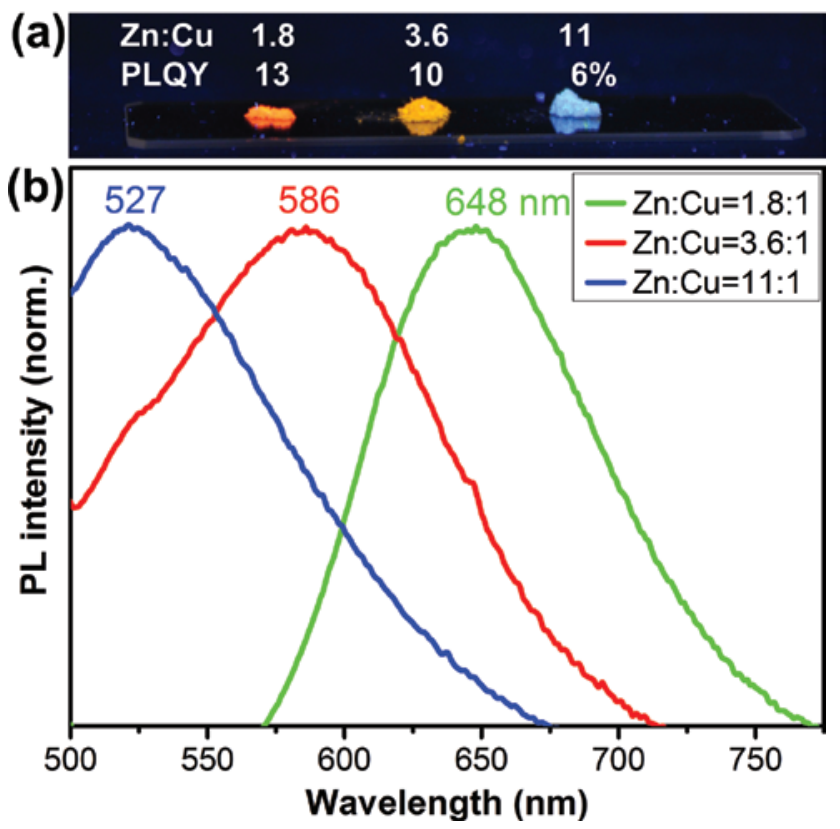

Fig. 6: Photos of CZIS/ZnS NCs-in-LiCl composites (initial ratios Zn:Cu=1.8, 3.6 and 11, synthesis with TOP:S) with corresponding PLQY values (a) and PL spectra (b).

The visible range is covered from $520 \mathrm{~nm}$ to $650 \mathrm{~nm}$ and in comparison with the PL maxima of the initial NC dispersions, a red shift of the emission is observed for the samples with initial ratios $\mathrm{Zn}: \mathrm{Cu}=1.8$ and 3.6 (Figure 7a and Table SI3). According to previous investigations, this red shift is mainly due to a slight aggregation of the NCs within LiCl. Furthermore, this phenomenon is also explained by the dipole-dipole interactions of the NCs with the salt [27, 40]. On the contrary, in the samples with larger $\mathrm{Zn:Cu}$ initial ratios (7.3 and 11), a blue shift is revealed, which is remarkably large for $\mathrm{Zn}: \mathrm{Cu}=7.3$, showing nearly the same emission as the sample with an initial ratio of $\mathrm{Zn}: \mathrm{Cu}=11$. Here we note that these measurements were reproduced on composites prepared approximately 2 years ago, that demonstrates excellent stability of the NCs encapsulated into the salt matrix.

We observed a decrease of the PLQY for the NCs-in-LiCl samples with initial ratios $\mathrm{Zn}: \mathrm{Cu}=1.8$, 3.6 and 7.3, which depends on the PLQY of the initial NC dispersions with the most pronounced drop in the case of the NCs with the initial ratio of $\mathrm{Zn:Cu}=1.8$ (Figure $7 \mathrm{~b}$, Table SI3). Apparently, the encapsulation into $\mathrm{LiCl}$ of $\mathrm{Zn}: \mathrm{Cu}=1.8$, 3.6 and 7.3 NC samples leads to the formation of defects on the NC surface resulting in an increase of non-radiative relaxation events. These defects may be related to the aggregation of the NCs during the crystallization 

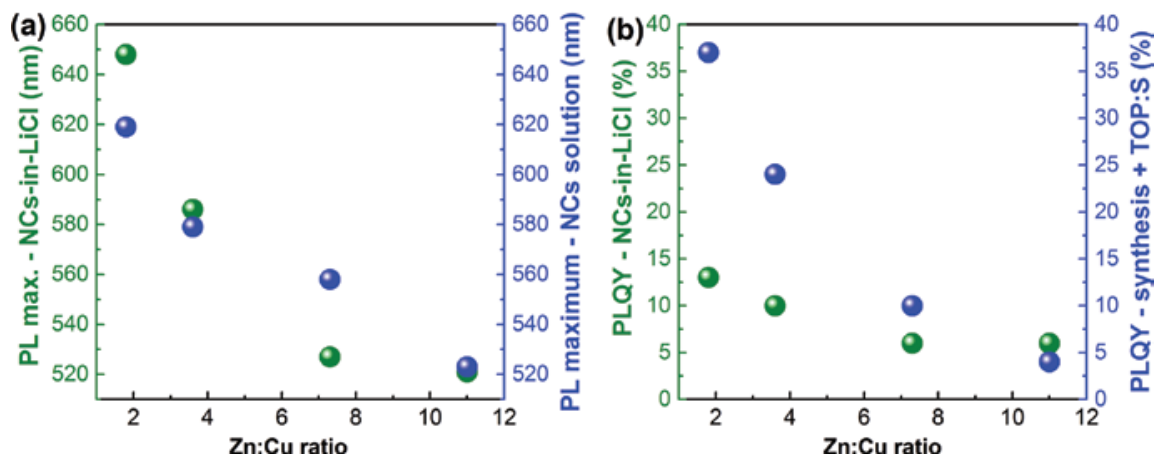

Fig. 7: Comparison of the PL maxima (a) and PLQYs (b) of the CZIS/ZnS NC dispersions (obtained with initial ratios $\mathrm{Zn}: \mathrm{Cu}=1.8-11$ and addition of TOP:S) and NCs-in-LiCl composites.

process, reflected in the red shift of the PL maximum. In contrast to this, for the $\mathrm{Zn}: \mathrm{Cu}=11$ sample (lowest PLQY of NC dispersion) a small increase of the PLQY is observed (Figure 7b, Table SI3).

Comparing two sets of the NCs-in-salt samples, one can see that embedding of CZIS/ZnS NCs into Borax salt leads to a small red shift of the PL maxima by 1-7 nm, while the emission spectra of the NCs-in-LiCl experience larger shifts to shorter and to longer wavelengths $(-31 \mathrm{~nm} \leq \Delta \mathrm{PL}$ maximum $\leq 29 \mathrm{~nm})$, summarized in Figure 8a. By incorporating the NCs into Borax their PLQYs increase with increasing $\mathrm{Zn}$ :Cu ratio $(6 \% \leq \Delta \mathrm{PLQY} \leq 11 \%)$, while by embedding the NCs into $\mathrm{LiCl}$ the PLQY decreases with increasing $\mathrm{Zn}: \mathrm{Cu}$ ratio $(-24 \% \leq \Delta \mathrm{PLQY} \leq 2 \%)$ (Figure $8 \mathrm{~b})$. Only for the sample with an initial ratio of $\mathrm{Zn}: \mathrm{Cu}=11$ a small increase in PLQY can
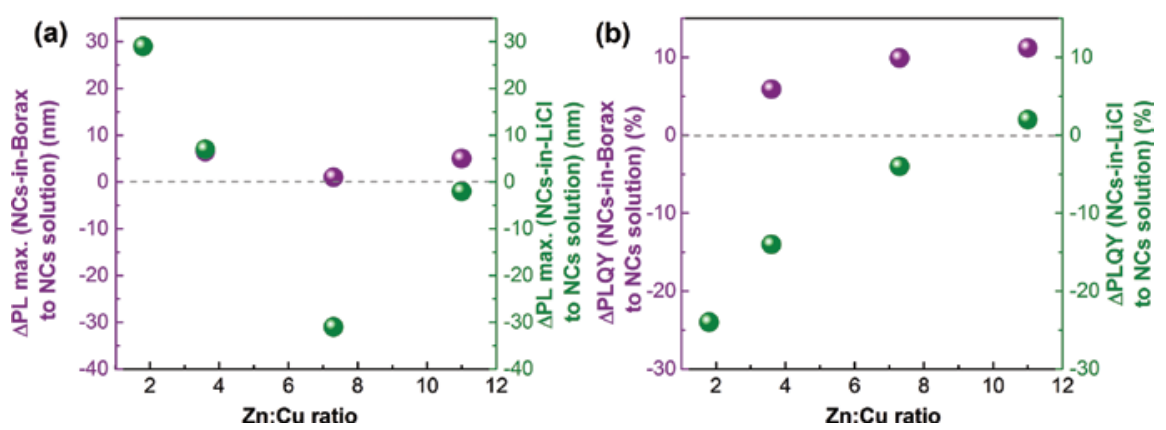

Fig. 8: Comparison of the difference in PL maxima (a) and PLQYs (b) of the CZIS/ZnS NC dispersions with NCs-in-salts. 
be seen for the NCs-in-LiCl powders. Overall, from the viewpoint of preservation of optical properties and in particular a bright luminescence of the parent NCs, Borax serves as a better matrix than $\mathrm{LiCl}$.

\subsection{Fabrication of a color conversion LED using CZIS/ZnS NCs-in-LiCl composite}

As a proof of concept, we designed a LED based on the CZIS/ZnS NCs-in-LiCl composite due to the simplicity of the crystallization process. A blue LED emitting at $460 \mathrm{~nm}$ was used as a back lighting source and red emitting NCs-in-LiCl $(\mathrm{Zn}: \mathrm{Cu}=1.8)$ with a PL maximum at $645 \mathrm{~nm}$ were chosen to serve as a color conversion material. The NCs-in-LiCl powder was encapsulated into conventional epoxy resin, which hardens without any heat or light treatment forming a film on the blue LED which is stable upon illumination [27]. The PL spectrum of the resulting device exhibit two peaks related to the chip (461 nm) and to the NCs $(648 \mathrm{~nm})$ (Figure 9). In order to further tune the color of the LED, in particular to achieve white light fluorescence, additional yellow emitting NCs-in-salt samples should be incorporated into the film with a proper balance between the intensities of each emission.

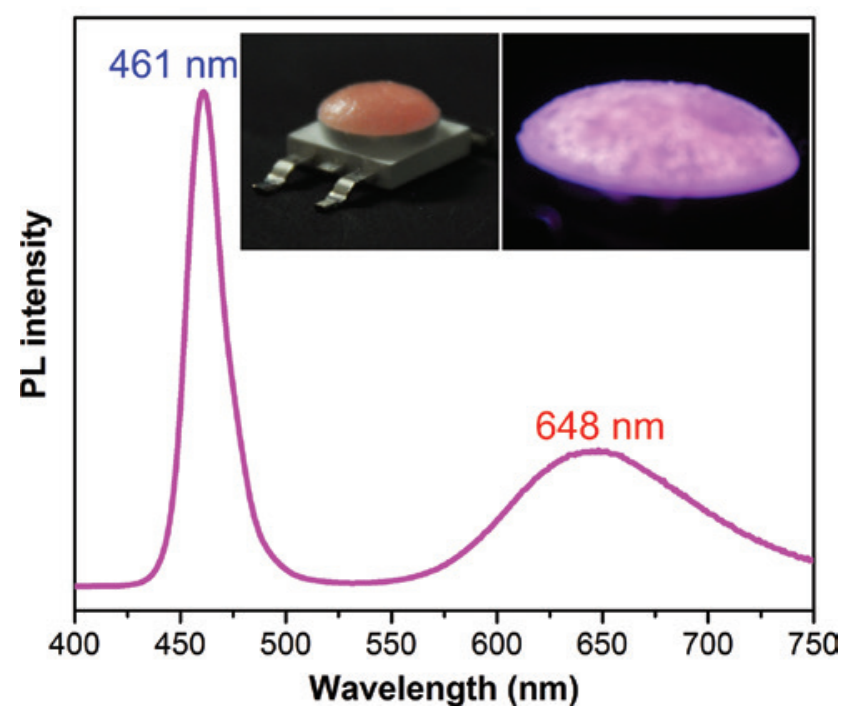

Fig. 9: PL spectrum and photos of the CZIS/ZnS NCs-in-LiCl based color conversion LED. 


\section{Conclusion}

We demonstrated the colloidal synthesis of CZIS/ZnS NCs starting with initial ratios of $\mathrm{Zn}: \mathrm{Cu}=1.8,3.6,7.3$ and 11. By adding TOP:S in the shell growth step, the PL of the resulting NCs could be extended, covering the range from $520 \mathrm{~nm}$ to $620 \mathrm{~nm}$ and leading to high PLQYs of up to $50 \%$. In order to prepare solid composites, two different embedding methods were investigated. In the first one the NCs were first transferred to the aqueous phase and then co-crystallized with Borax, whereas in the second we directly used as-synthesized nanoparticles dissolved in tetrahydrofuran to incorporate them into LiCl. Among these two matrices Borax demonstrated a better passivation of the NCs reflected by increased PLQYs $(6 \% \leq \Delta \mathrm{PLQY} \leq 11 \%)$ with only small shifts of the PL maxima (1 $\mathrm{nm} \leq \Delta \mathrm{PL}$ maximum $\leq 7 \mathrm{~nm}$ ). In contrast, the encapsulation of the NCs into $\mathrm{LiCl}$ led to a remarkable decrease of the PLQYs $(-24 \% \leq \Delta \mathrm{PLQY} \leq 2 \%)$ and large blue and red shifts of the PL maxima ( $-31 \mathrm{~nm} \leq \Delta \mathrm{PL}$ maximum $\leq 29 \mathrm{~nm})$. Furthermore, as a proof of concept, we fabricated a color conversion LED using NCs-in-LiCl solid composite.

Acknowledgments: We are grateful to S. Goldberg and Dr. J. Simmchen (TU Dresden) for TEM imaging. This work was supported by the German Research Foundation (DFG) under Projects LE 3877/1-1 and EY 16/14-3.

\section{Associated content}

Supporting information: TEM images of CZIS/ZnS NCs obtained with and without TOP:S; Table comparing PLQYs and PL maxima of CZIS/ZnS NCs synthesized by varying initial ratio of $\mathrm{Zn}: \mathrm{Cu}$ from 1.8 to 11 with and without TOP:S in the shell growth step; Table with comparison of PLQYs and PL maxima of CZIS/ZnS NCs (obtained with $\mathrm{Zn:Cu}=3.6,7.3,11$ ) in dispersion and in Borax matrix; Table comparing PLQYs and PL maxima of CZIS/ZnS NCs (obtained with Zn:Cu=1.8-11 and TOP:S addition) in dispersion and in $\mathrm{LiCl}$ matrix.

\section{References}

1. B. G. D. Scholes, Adv. Funct. Mater. 18 (2008) 1157.

2. D. V. Talapin, J. S. Lee, M. V. Kovalenko, E. V. Shevchenko, Chem. Rev. 110 (2010) 389.

3. M. V. Kovalenko, L. Manna, A. Cabot, Z. Hens, D. V. Talapin, C. R. Kagan, V. I. Klimov, A. L. Rogach, P. Reiss, D. J. Milliron, P. Guyot-Sionnnest, G. Konstantatos, W. J. Parak, T. Hyeon, B. A. Korgel, C. B. Murray, W. Heiss, ACS Nano 9 (2015) 1012.

4. I. J. Kramer, E. H. Sargent, Chem. Rev. 114 (2014) 863. 
5. G. H. Carey, A. L. Abdelhady, Z. Ning, S. M. Thon, O. M. Bakr, E. H. Sargent, Chem. Rev. 115 (2015) 12732.

6. L. Li, T. J. Daou, I. Texier, T. T. K. Chi, N. Q. Liem, P. Reiss, Chem. Mater. 21 (2009) 2422.

7. T. Pons, E. Pic, N. Lequeux, E. Cassette, L. Bezdetnaya, F. Guillemin, F. Marchal, B. Dubertret, ACS Nano 4 (2010) 2531.

8. E. Arici, N. S. Sariciftci, D. Meissner, Adv. Funct. Mater. 13 (2003) 165.

9. H. Nakamura, W. Kato, M. Uehara, K. Nose, T. Omata, S. Otsuka-Yao-Matsuo, M. Miyazaki, H. Maeda, Chem. Mater. 18 (2006) 3330.

10. R. Xie, M. Rutherford, X. Peng, J. Am. Chem. Soc. 131 (2009) 5691.

11. S.L. Castro, S. G. Bailey, R. P. Raffaelle, K. K. Banger, A. F. Hepp, J. Phys. Chem. B 108 (2004) 12429.

12. W. Zhang, X. Zhong, Inorg. Chem. 50 (2011) 4065.

13. H.-J. Pan, C.-W. Lai, S.-W. Chou, P.-T. Chou, Mater. Express 2 (2012) 224.

14. R. Lesyuk, B. Cai, U. Reuter, N. Gaponik, D. Popovych, V. Lesnyak, Small Methods 1 (2017) 1700189.

15. F. Meinardi, H. McDaniel, F. Carulli, A. Colombo, K. A. Velizhanin, N. S. Makarov, R. Simonutti, V. I. Klimov, S. Brovelli, Nat. Nanotechnol. 10 (2015) 878.

16. R. Sumner, S. Eiselt, T. B. Kilburn, C. Erickson, B. Carlson, D. R. Gamelin, S. McDowall, D. L. Patrick, J. Phys. Chem. C 121 (2017) 3252.

17. R. Lesyuk, V. Lesnyak, A. Herguth, D. Popovych, Y. Bobitski, C. Klinke, N. Gaponik, J. Mater. Chem. C 5 (2017) 11790.

18. T. Otto, M. Müller, P. Mundra, V. Lesnyak, H. V. Demir, N. Gaponik, A. Eychmüller, Nano Lett. 12 (2012) 5348.

19. M. Müller, M. Kaiser, G. M. Stachowski, U. Resch-Genger, N Gaponik, A. Eychmüller, Chem. Mater. 26 (2014) 3231.

20. M. Adam, Z. Wang, A. Dubavik, G. M. Stachowski, C. Meerbach, Z. Soran-Erdem, C. Rengers, H. V. Demir, N. Gaponik, A. Eychmüller, Adv. Funct. Mater. 25 (2015) 2638.

21. M. Adam, R. Tietze, N. Gaponik, A. Eychmüller, Z. Phys. Chem. 229 (2015) 109.

22. M. Adam, T. Erdem, G. M. Stachowski, Z. Soran-Erdem, J. F. L. Lox, C. Bauer, J. Poppe, H. V. Demir, N. Gaponik, A. Eychmüller, ACS Appl. Mater. Interfaces 7 (2015) 23364.

23. S. Kalytchuk, M. Adam, O. Tomanec, R. Zbořil, N. Gaponik, A. L. Rogach, ACS Photonics 4 (2017) 1459.

24. M. Adam, N. Gaponik, A. Eychmüller, T. Erdem, Z. Soran-Erdem, H. V. Demir, J. Phys. Chem. Lett. 7 (2016) 4117.

25. C. Guhrenz, A. Benad, C. Ziegler, D. Haubold, N. Gaponik, A. Eychmüller, Chem. Mater. 28 (2016) 9033.

26. A. Benad, C. Guhrenz, C. Bauer, F. Eichler, M. Adam, C. Ziegler, N. Gaponik, A. Eychmüller, ACS Appl. Mater. Interfaces 8 (2016) 21570.

27. T. Erdem, Z. Soran-Erdem, V. K. Sharma, Y. Kelestemur, M. Adam, N. Gaponik, H. V. Demir, Nanoscale 7 (2015) 17611.

28. T. Erdem, Z. Soran-Erdem, P. L. Hernandez-Martinez, V. K. Sharma, H. Akcali, I. Akcali, N. Gaponik, A. Eychmüller, H. V. Demir, Nano Res. 8 (2014) 860.

29. W. K. Bae, K. Char, H. Hur, S. Lee, Chem. Mater. 20 (2008) 531.

30. M. Grabolle, M. Spieles, V. Lesnyak, N. Gaponik, A. Eychmüller, U. Resch-Genger, Anal. Chem. 81 (2009) 6285.

31. J. C. De Mello, H. F. Wittmann, R. Friend, Adv. Mater. 9 (1997) 230.

32. H. Zhong, Y. Zhou, M. Ye, Y. He, J. Ye, C. He, C. Yang, Y. Li, Chem. Mater. 20 (2008) 6434. 
33. J. Feng, M. Sun, F. Yang, X. Yang, Chem. Commun. 47 (2011) 6422.

34. I. Tsuji, H. Kato, H. Kobayashi, A. Kudo, J. Phys. Chem. 109 (2005) 7323.

35. L. De Trizio, L. Manna, Chem. Rev. 116 (2016) 10852.

36. G. B. Dhanaraj, V. K. Prasad, M. Dudley, Handbook of Crystal Growth, Springer, New York, 2010.

37. A. Holden, P. Morrison, Crystals and crystal growing, MIT Press, Cambridge, MA, 1982.

38. K.-T. Wilke, J. Bohm, Kristallzüchtung (in German), Harri Deutsch Verlag, Frankfurt am Main, 1988.

39. S. Kalytchuk, O. Zhovtiuk, A. L. Rogach, Appl. Phys. Lett. 103 (2013) 103105.

40. K. H. Ibnaouf, S. Prasad, M. S. A. Salhi, A. Hamdan, M. B. Zaman, L. E. Mir, J. Luminescence 149 (2014) 369.

Supplementary Material: The online version of this article offers supplementary material (https://doi.org/10.1515/zpch-2017-1086). 